\title{
Detecção do vírus da Artrite Encefalite Caprina por nested PCR e nested RT-PCR em ovócitos e fluido uterino
}

\author{
Caprine Arthritis Encephalitis virus is detected in \\ oocytes and uterine fluid by nested PCR and nested RT-PCR
}

\author{
Francisco Roger Aguiar Cavalcante ${ }^{1}$, Alice Andrioli ${ }^{2 *}$, Raymundo Rizaldo Pinheiro ${ }^{2}$ \\ Kelma Costa de Souza ${ }^{3}$, Ana Kamila Andrade Veras ${ }^{4}$, Tânia Azevedo Lopes ${ }^{4}$, \\ Solange Damasceno Sousa ${ }^{4}$, Pedro Alberto Freitas da Silva ${ }^{4}$
}

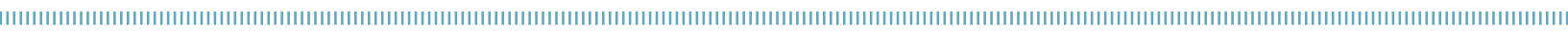

RESUMO: A Artrite Encefalite Caprina (CAE) é uma enfermidade infectocontagiosa causada por um vírus pertencente ao gênero lentivírus, denominado de vírus da Artrite Encefalite Caprina (CAEV). O CAEV é encontrado em vários tecidos, como o nervoso, o pulmonar, o da glândula mamária e do trato genital masculino e feminino. Desta forma, objetivou-se com este trabalho identificar a presença do CAEV, pelas técnicas de diagnóstico moleculares, em ovócitos e fluido uterino, visando avaliar a possibilidade de transmissão do CAEV pela reprodução. Foram selecionadas 13 cabras comprovadamente infectadas, as quais foram submetidas à eutanásia para coleta do aparelho reprodutor, aspiração do fluido uterino e dissecção dos ovários para coleta de ovócitos. Para identificaçáo do CAEV nas amostras coletadas, na forma de provírus e na forma livre, foram realizadas as técnicas de PCRn e RT-PCRn, respectivamente. Observaram-se que 53,8\% dos ovócitos foram positivos à técnica de RT-PCRn, enquanto apenas $9,1 \%$ foram positivos à PCRn. A técnica de RT-PCRn também identificou o vírus no fluido uterino de $46,1 \%$ das fêmeas testadas. Embora as 13 cabras em experimento fossem portadoras do CAEV, 30,8\% apresentaram resultados negativos na PCRn e RT-PCRn em todas as amostras analisadas (ovócito e fluido uterino). Conclui-se que a PCRn e a RT-PCRn podem ser utilizadas no diagnóstico da CAE tendo os ovócitos e o fluido uterino como materiais de análise, e que a presença do CAEV nestes materiais aponta para o risco da transmissão do CAEV através das tecnologias reprodutivas aplicadas às fêmeas.

PALAVRAS-CHAVE: cabra; diagnóstico; reprodução; lentivírus; CAEV.

\begin{abstract}
Caprine arthritis-encephalitis (CAE) is an infectious disease caused by the caprine arthritis-encephalitis virus (CAEV), belonging to the lentivirus genus. The presence of the virus has been observed in the nervous system, respiratory tract and mammary gland, and also in the male and female genital tract. The objective of this study is to identify the virus in oocyte and uterine fluid of infected goats by molecular diagnostic techniques, in order to assess the possibility of CAEV transmission with reproduction. Thirteen infected goats were selected and submitted to euthanasia for the collection of the reproductive system, aspiration of the uterine fluid and dissection of ovaries for oocyte collection. In order to identify the CAEV in the collected material, in the protovirus and free forms, it was submitted to the nRT-PCR and nPCR techniques, respectively. As a result, it was observed that $53.8 \%$ of oocytes were positive to nRT-PCR, while only $9.1 \%$ were positive to nPCR. The nRT-PCR also identified the virus in the uterine fluid of $46.1 \%$ of the tested females. Even though the 13 goats had CAEV, $30.8 \%$ presented negative results in nPCR and nRTPCR in all of the analyzed samples (oocyte and uterine fluid). This work concludes that nRT-PCR and nPCR can be used in the diagnosis of CAE for the analysis with oocytes and uterine fluid, and that the presence of CAEV in these materials points out to the risk of CAEV transmission through reproductive technologies used in females.
\end{abstract}

KEYWORDS: goat; diagnosis; reproduction; lentivirus; CAEV.

\footnotetext{
'Universidade Estadual Vale do Acaraú - Sobral (CE), Brasil.

${ }^{2}$ Embrapa Caprinos e Ovinos - Sobral (CE), Brasil.

${ }^{3}$ Universidade Estadual do Ceará - Fortaleza (CE), Brasil.

${ }^{4}$ Fundação Cearense de Apoio ao Desenvolvimento Científico e Tecnológico (FUNCAP) - Sobral (CE), Brasil.

*Autor correspondente: alice.andrioli@embrapa.br

Recebido em: 30/11/11. Aceito em: 12/08/2013
} 


\section{INTRODUÇÃO}

A Artrite Encefalite Caprina (CAE) é uma enfermidade infecciosa, presente na maioria dos países nos quais a caprinocultura é uma atividade de importância econômica.

Animais acometidos por esta doença são reservatórios e fonte de infecção, e podem apresentar sintomas com severidade variada, porém, podem permanecer assintomáticos por um período longo de tempo após serem infectados (Robinson; Ellis, 1986), sendo que o vírus da Artrite Encefalite Caprina (CAEV) tem como principais células-alvo os monócitos presentes no sangue e os macrófagos do sistema nervoso, articulaçóes, aparelho respiratório e glândula mamária.

O CAEV também foi encontrado no sêmen e no órgáo sexual de reprodutores (ANDrioli et al., 2006; Peterson et al., 2008), o que sugere que a infecção venérea seja uma possibilidade. Souza et al. (2013), visando testar esta hipótese, inseminaram 20 cabras com sêmen infectado artificialmente com o CAEV, e verificaram que todas soro converteram entre 30 e 60 dias após a inseminação.

Estudos realizados com tecidos do aparelho reprodutor de fêmeas demonstraram que as células da granulosa e células epiteliais de oviduto podem replicar o CAEV in vitro (Lamara et al., 2001; 2002). Além disso, o CAEV foi encontrado em secreçóes uterinas e em células da granulosa, mas não em ovócitos e embriôes (ANDrioli, 2001; Fieni et al., 2003; Ali Al Ahmad et al., 2005; 2008). No entanto, ANDrioli et al. (2002) obtiveram crias negativas de cabras infectadas pelo CAEV através da transferência de embriōes (TE).

Reconhecendo a presença do CAEV no aparelho reprodutor feminino e a possibilidade de transmissão do vírus por técnicas reprodutivas, objetivamos identificar o vírus em ovócitos e no fluido uterino de cabras comprovadamente infectadas através das técnicas de PCRn e RT-PCRn, as quais detectam o vírus integrado à célula e na forma livre, respectivamente.

\section{MATERIAIS E MÉTODOS}

O presente trabalho foi realizado no Laboratório de Biotecnologia da Reprodução da Embrapa Caprinos e Ovinos, localizado no município de Sobral, regiáo Norte do Estado do Ceará. O experimento compreendeu os meses de agosto de 2010 a fevereiro de 2011.

\section{Seleção dos animais experimentais}

Foram selecionadas para o experimento 13 fêmeas da espécie caprina, sem raça definida (SRD), com idades entre quatro e cinco anos, as quais foram contaminadas, em experimento anterior, por sêmen com o CAEV (título de $10^{2}$ $\mathrm{TCID}_{50} / \mathrm{mL}$ a $10^{6} \mathrm{TCID}_{50} / \mathrm{mL}$ ), via inseminação artificial (IA) (Souza et al., 2013).

As cabras portavam o vírus há 24 meses, segundo testes de Imunodifusão em Gel de Agarose (Gouveia et al., 2000) e Western Blot (Rodrigues et al., 2009; adaptado de Pinheiro, 2001), realizados 30 e 60 dias após a IA. Os mesmos testes foram repetidos nas 13 cabras para avaliação do perfil sorológico antes das coletas dos ovócitos.

\section{Sincronização do estro}

Com a finalidade de recuperar ovócitos de folículos em diferentes fases de desenvolvimento, incluindo os pré-ovulatórios, as fêmeas foram submetidas à sincronizaçâo hormonal do estro com a utilização de esponjas intravaginais impregnadas com $60 \mathrm{mg}$ de acetato de medroxiprogesterona (MAP), que foram inseridas e mantidas na regiáo cranial da vagina durante 11 dias, sendo considerado o dia zero como sendo o dia da introduçáo da esponja. No nono dia, houve a aplicação intramuscular de $50 \mu \mathrm{g}$ de cloprostenol e 200 UI de gonadotropina coriônica equina (eCG), e no $11^{\circ}$ dia a fonte de progesterona foi retirada.

\section{Coleta de material}

Os animais foram submetidos à eutanásia, segundo normas do Conselho Nacional de Controle da Experimentaçấo Animal (CONCEA). Após evisceração, o aparelho reprodutor foi retirado, a bexiga foi esvaziada e o material foi acondicionado em bacias com gelo, sendo devidamente identificado. Por fim, foi conduzido ao laboratório.

Realizou-se a aspiração de fluido uterino com uma seringa de $5 \mathrm{~mL}$ e agulha de $40 \times 12 \mathrm{~mm}$ após administração de $5 \mathrm{~mL}$ de tampão fosfato-salino (PBS). O líquido aspirado foi acondicionado em tubos estéreis de fundo cônico de 1,5 mL.

Os ovários foram dissecados do aparelho reprodutor e lavados com álcool a $70 \%$ e, em seguida, com soluçấo de PBS, abundantemente. Em seguida, eles foram cortados com lâmina de bisturi em uma placa de Petri contendo soluçâo de PBS e soro fetal a $1 \%$, à temperatura ambiente, para liberação dos ovócitos.

O material foi então observado sob estereomicroscópio, em que os ovócitos foram transferidos para um meio de PBS e $0,4 \%$ de albumina sérica bovina (BSA). Estes foram agitados com a pipeta de manipulação até a soltura das células da granulosa e, em seguida, repassados para outro meio de PBS e BSA ( $0,4 \%)$, sendo avaliados quanto à qualidade e à integridade da zona pelúcida.

Os ovócitos de qualidade I a III, de acordo com suas características morfológicas e com zona pelúcida íntegra, foram divididos igualmente para serem submetidos à extração de 
DNA para PCRn e à extração de RNA, visando à realização da RT-PCRn. Aqueles destinados à RT-PCRn foram transferidos para tubo de $0,5 \mathrm{~mL}$ de fundo cônico com $350 \mu \mathrm{L}$ de tampáo RA1 e 3,5 $\mu \mathrm{L}$ de $\beta \mathrm{ME}$ (beta-mercaptoetanol), sendo que o volume total das amostras contendo os ovócitos não ultrapassou $40 \mu \mathrm{L}$, e as extraçốes foram feitas com o kit NucleoSpin ${ }^{\circledast}$ RNA II (Marcherey-Nagel), segundo as instruçóes do fabricante (SIDER et al., 2010).

As amostras de fluido uterino foram centrifugadas a

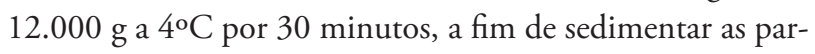
tículas virais e eventuais células. $\mathrm{O}$ sobrenadante foi descartado e o pellet suspendido novamente em $350 \mu \mathrm{L}$ de tampáo RA1 e 3,5 $\mu \mathrm{L}$ de $\beta \mathrm{ME}$. Imediatamente foi feita a extraçáo de RNA pelo mesmo procedimento descrito para os ovócitos (Sider et al., 2010).

A síntese de cDNA foi realizada com o kit Improm II (Reverse reaction for detection of caprine arthritis-encephalitis - Transcription System), segundo as instruçôes do fabricante.

$\mathrm{Na}$ amplificação do cDNA, todos os oligonucleotídeos iniciadores foram determinados a partir da regiáo do gene estrutural gag da amostra padráo CAEV-Cork (Saltarelli et al., 1990). O cDNA foi amplificado inicialmente com um par de iniciadores externos (primers 1 - 5'-caagcagcaggagggagaagctg- 3 ' e 2 - 5'tcctacccccataatttgatccac-3'), resultando na amplificação de um fragmento de DNA de 296pb. O produto desta amplificação foi, então, amplificado novamente com iniciadores internos (primers 3 - 5'-gttccagcaactgcaaacagtagcaatg- $3^{\prime}$ e $4-5^{\prime}$-acctttctgcttcttcatttaatttccc $-3^{\prime}$ ), descritos por BARLOUGH et al., (1994), resultando em um fragmento de $187 \mathrm{pb}$.

As condiçôes de amplificação são realizadas segundo metodologia descrita por BARLOUGH et al. (1994), com modificaçôes (ANDrioli et al., 2006).

Os ovócitos destinados à extração do DNA pró-viral foram transferidos juntamente com um volume de meio de $40 \mu \mathrm{L}$, para tubo de $0,5 \mathrm{~mL}$ de fundo cônico, com $350 \mu \mathrm{L}$ de tampão hipertônico ( $0,32 \mathrm{M}$ de sacarose, $10 \mathrm{mM}$ cloridrato de Trisma, $\mathrm{pH} 7,5 ; 5,0 \mathrm{mM} \mathrm{MgCl} 2 ; 1,0 \%$ Triton X 100) e mantidos durante 2 minutos em temperatura ambiente. Em seguida, o material foi centrifugado $(2500 \mathrm{rpm} / 10 \mathrm{mi}-$ nutos) e o sedimento foi lavado com $500 \mu \mathrm{L}$ de PBS, sendo submetido novamente à centrifugação.

$\mathrm{O}$ material foi suspendido novamente e homogeneizado em $250 \mathrm{~mL}$ de tampão (10 mM tris $\mathrm{HCl}, \mathrm{pH} 8,0 ; 50 \mathrm{mM} \mathrm{KCl}$; $1,0 \mathrm{mM} \mathrm{MgCl} ; 5 \%$ glicerol; $0,05 \%$ Tween 20) e tratado com $2,5 \mathrm{~mL}$ de proteinase $\mathrm{K}(0,1 \mu \mathrm{g} / \mathrm{mL})$ durante 60 minutos, em banho-maria, a $56^{\circ} \mathrm{C}$. Após este tempo, a proteinase $\mathrm{K}$ foi inativada termicamente em água fervente $\left(100^{\circ} \mathrm{C}\right)$ durante 10 minutos. As amostras foram acondicionadas na geladeira por 24 horas e, posteriormente, no freezer a $-20^{\circ} \mathrm{C}$, até a realização da PCRn. A amplificaçấo do DNA pró-viral foi realizada pelo mesmo procedimento descrito para o cDNA.
Os produtos de amplificação das amostras $(15 \mathrm{~mL})$ e os controles positivos e negativos, juntamente com o marcador molecular (100pb DNA Ladder, Sigma), foram submetidos à eletroforese em gel de agarose a $1 \% \mathrm{em} \mathrm{TBE} \mathrm{(Tris,} \mathrm{borato} \mathrm{e}$ EDTA $0,1 \mathrm{X}$ ) e corados com brometo de etídio, visualizados sob luz ultravioleta em transiluminador.

O resultado da PCRn foi comprovado por sequenciamento dos seus produtos, que resultaram em amplificaçáo de um fragmento de DNA próximo ao esperado (187pb), a partir de amostras de ovócito, fluido uterino e sangue.

\section{RESULTADOS E DISCUSSÃO}

Observaram-se neste experimento que 53,8\% (7/13) dos animais apresentaram resultados positivos à técnica de RT-PCRn em ovócitos (Tabela 1 e Fig. 1), o que indica que o CAEV está presente neste material na forma livre, possivelmente aderido à zona pelúcida. A PCRn identificou apenas uma amostra de ovócito positivo dentre as 11 avaliadas $(9,1 \%)$, indicando a presença do DNA pró-viral nesta amostra (Tabela 1). Estes resultados corroboram os de Ali Al Ahmad et al. (2006) que, utilizando técnicas moleculares como a PCRn e a RT-PCRn, verificaram que células embrionárias são suscetíveis e permissivas ao CAEV. Diferentemente, Ali Al Ahmad et al. (2005) não verificaram a presença do DNA pró-viral do CAEV em ovócitos de folículos antrais, mas sim em células da granulosa de cabras infectadas naturalmente.

A técnica de RT-PCRn também identificou o vírus na forma de RNA no fluido uterino em 46,1 \% (6/13) das fêmeas testadas. Da mesma forma, ANDrioli (2001), utilizando a técnica de PCRn, detectou o DNA pró-viral em fluido uterino em $70 \%$ das cabras infectadas naturalmente pelo CAEV, submetidas ao processo de coleta e transferência de embriôes.

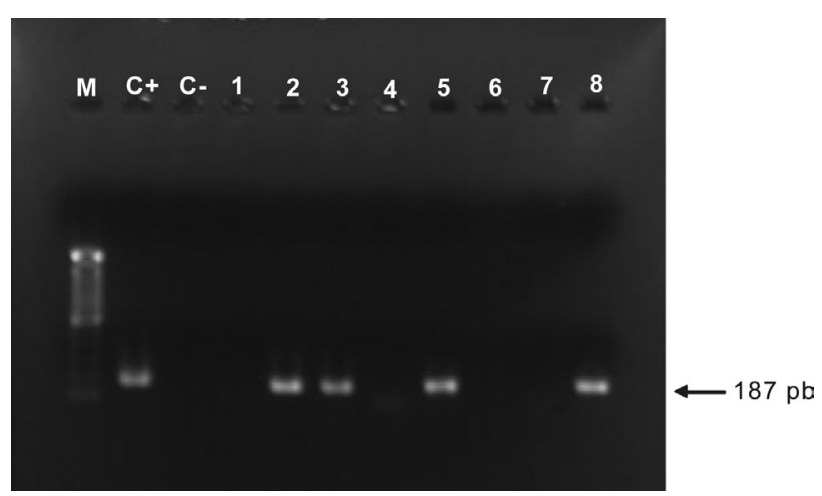

M: marcador DNA; C+: controle positivo; C-: controle negativo; 2, 3, 5 e 8: amostras positivas; 1, 4, 6 e 7: amostras negativas.

Figura 1. Gel de agarose $1 \%$ corado com brometo de etídio. Reação em cadeia de polimerase - nested RT-PCR - de amostras de ovócitos de cabras infectadas com o vírus da Artrite Encefalite Caprina, bandas de 187pb. 
Embora as 13 cabras em experimento fossem portadoras do CAEV, quatro $(30,8 \%)$ apresentaram resultados negativos na PCRn e na RT-PCRn em todas as amostras analisadas (ovócito e fluido uterino). Das nove cabras positivas na RT-PCRn, segundo os resultados obtidos em amostras de fluido e ovócitos, em quatro $(30,7 \%)$ o RNA viral foi identificado nos dois materiais, e em cinco $(38,5 \%)$ em apenas um deles (Tabela 1).

Nas amostras de sangue coletadas (24 meses após a infecção), a PCRn identificou sete fêmeas positivas (53,85\%), enquanto os testes imunológicos de Western Blot (WB), Elisa e Imunodifusão em Gel de Agarose (IDGA) identificaram 23,08, 38,46 e 0\%, respectivamente (Tabela 2). Isso demonstra que, possivelmente, o genoma do vírus se encontre integrado às células do sangue. Observaram-se também que três animais (animais no 7, 10 e 11) foram negativos em todos os testes realizados no sangue (WB, Elisa, IDGA e PCRn), embora fossem animais sabidamente infectados e que apresentaram, neste experimento, resultados positivos nas provas de PCRn em ovócito (animal no 7 ) e RT-PCR nos ovócitos (animais no 7, 10 e 11) e no fluido uterino (animais no 10 e 11).

Por outro lado, quatro animais negativos ao PCRn e RT-PCRn, quando analisados os ovócitos e fluido uterino (animais $\mathrm{n}^{\circ} 2,8,9$ e 12), mostraram-se positivos a pelo menos um dos testes realizados em suas amostras sanguíneas.

No total, foram realizados 89 testes nas 13 cabras: quatro foram feitos em amostras de sangue (três sorológicos e um molecular) e três técnicas moleculares em material do aparelho reprodutor feminino. Em 32,5\% dos testes

Tabela 1. Resultados de PCRn e RT-PCRn para identificação de DNA pró-viral e do RNA do vírus da Artrite Encefalite Caprina em amostras de ovócitos e fluido uterino de cabras infectadas por inseminação artificial com sêmen contaminado.

\begin{tabular}{lccc} 
& \multicolumn{2}{c}{ Ovócito } & $\begin{array}{c}\text { Fluido } \\
\text { Uterino }\end{array}$ \\
\cline { 2 - 4 } Animal & PCRn & RT-PCRn & RT-PCRn \\
\hline 02 & negativo & positivo & positivo \\
\hline 03 & negativo & negativo & negativo \\
\hline 04 & - & positivo & negativo \\
\hline 05 & negativo & negativo & positivo \\
\hline 06 & negativo & positivo & negativo \\
\hline 07 & negativo & positivo & positivo \\
\hline 08 & positivo & positivo & negativo \\
\hline 09 & - & negativo & negativo \\
\hline 10 & negativo & negativo & negativo \\
\hline 11 & negativo & positivo & positivo \\
\hline 12 & negativo & positivo & positivo \\
\hline 13 & negativo & negativo & negativo \\
\hline Total de & negativo & negativo & positivo \\
\hline positivos & $9,1 \%$ & $53,8 \%$ & $46,1 \%$ \\
\hline
\end{tabular}

realizados (29/89) foram obtidos resultados positivos 26 meses após o desafio com sêmen infectado e 24 meses após a confirmação da infecção por WB e IDGA.

Estes resultados demonstram a complexidade do diagnóstico da CAE, pois somente ao aliar os testes imunológicos (IDGA, Elisa e WB) e moleculares em sangue, ovócito e fluido uterino foi possível demonstrar a positividade de $100 \%$ dos animais, sabidamente portadores do CAEV, após meses da infecção.

$O$ fato de a técnica de IDGA não ter confirmado o diagnóstico desses animais leva à hipótese de uma possível diminuição dos títulos de anticorpos nesta fase da infecção. Possivelmente devido ao sistema de criação semiextensivo ao qual foram mantidas, o pouco contato entre os animais levou ao insuficiente ou nenhum desafio do sistema imunológico para a produção de anticorpos.

A técnica molecular de PCRn se apresentou mais reagente no sangue (7/13) do que nos ovócitos (1/11) neste experimento, confirmando que o DNA pró-viral pode estar mais presente em células sanguíneas do que em células do aparelho reprodutivo. No entanto, o animal no 7 que se apresentou negativo ao PCR no sangue, mas foi reagente ao PCR em ovócito, confirmando a necessidade de associação de mais de um tipo de amostra para o diagnóstico da CAE.

Dentre as técnicas sorológicas, o Elisa se apresentou como a mais sensível, com 38,46\% (5/13) dos animais reagentes, seguido do WB, com $23,08 \%$. Um ponto importante a ser considerado é que, com o passar do tempo, o vírus tende a ficar quiescente nos animais infectados, provavelmente com DNA pró-viral não integrado ou integrado sem ativação.

Tabela 2. Resultados de Imunodifusão em Gel de Agarose, Western Blot, Elisa e PCRn para identificação de anticorpos e DNA pró-viral do vírus da Artrite Encefalite Caprina em amostras de soro e sangue de cabras infectadas artificialmente há dois anos por inseminação artificial com sêmen contaminado.

\begin{tabular}{lcccc}
\multirow{2}{*}{ Animal } & \multicolumn{4}{c}{ Sangue } \\
\cline { 2 - 5 } 01 & IDGA & WB & Elisa & PCRn \\
\hline 02 & negativo & positivo & negativo & positivo \\
\hline 03 & negativo & negativo & positivo & positivo \\
\hline 04 & negativo & negativo & negativo & positivo \\
\hline 05 & negativo & negativo & negativo & positivo \\
\hline 06 & negativo & negativo & negativo & positivo \\
\hline 07 & negativo & negativo & negativo & positivo \\
\hline 08 & negativo & negativo & negativo & negativo \\
\hline 09 & negativo & positivo & positivo & negativo \\
\hline 10 & negativo & negativo & positivo & positivo \\
\hline 11 & negativo & negativo & negativo & negativo \\
\hline 12 & negativo & negativo & negativo & negativo \\
\hline 13 & negativo & negativo & positivo & negativo \\
\hline Total de & negativo & positivo & positivo & negativo \\
\hline positivos & O\% & $23,08 \%$ & $38,46 \%$ & $53,85 \%$ \\
\hline & & & & \\
\hline
\end{tabular}

(-) Parcela perdida 
$\mathrm{O}$ sequenciamento dos produtos amplificados de amostra de sangue, do fluido uterino e do controle positivo (DNA pró-viral de células de membrana sinovial infectadas) apresentaram o máximo de 97, 97 e 98\% de identidade com sequências do gene gag do vírus da CAE, cepa Cork, respectivamente (ZHANG et al., 2000), comprovando os diagnósticos. Já o produto amplificado de ovócito não resultou em uma sequência válida, provavelmente devido a problemas na purificação da amostra.

\section{CONCLUSÕES}

A presença do DNA pró-viral do CAEV em ovócitos sugere que o vírus esteja integrado a estes ou à célula da granulosa ainda aderida à sua zona pelúcida.

Os ovócitos e o fluido uterino de animais infectados contêm o CAEV na forma livre, podendo ser identificado por RT-PCRn, sendo que nos ovócitos o vírus pode estar aderido à zona pelúcida.

Cabras portadoras do CAEV e, por vezes, não responsivas aos testes de diagnóstico do vírus no sangue, oferecem potencial risco de transmissão do CAEV pelas técnicas reprodutivas.

As técnicas moleculares são complementares às sorológicas para a identificação de animais infectados nos rebanhos.

\section{AGRADECIMENTOS}

À Fundação Cearense de Apoio ao Desenvolvimento Científico e Tecnológico (FUNCAP), pelo apoio financeiro. Ao curso de pós-graduação em Zootecnia da Universidade Estadual Vale do Acaraú (UVA) e ao Centro Nacional de Pesquisa em Caprinos e Ovinos (CNPC/EMBRAPA).

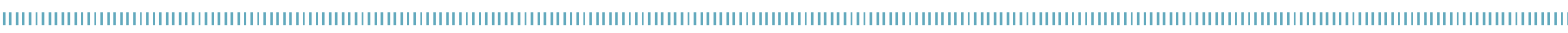

\section{REFERÊNCIAS}

ALI AL AHMAD, M.Z.; FIENI, F.; MARTIGNAT, L.; CHATAGNON, G.; BARIL, G.; BOUVIER, F.; CHEBLOUNE, Y. Proviral DNA of caprine arthritis encephalitis virus (CAEV) is detected in cumulus oophorus cells but not in oocytes from naturally infected goats. Theriogenology, v.64, n.7, p.1656-1666, 2005.

ALI AL AHMAD, M.Z.; FIENI, F.; GUIGEN, F.; LARRAT, M.; PELLERIN, J.L.; ROUX, C.; CHEBLOUNE, Y. Cultured early goat embryos and cells are susceptible to infection with caprine encephalitis virus. Virology, v.353, n.2, p.307-315, 2006.

ALI AL AHMAD, M.Z.; FIENI, F.; PELLERIN, J.L.; GUIGEN, F.; CHEREL, Y.; CHATAGNON, G.; BOUZAR, A.B.; CHEBLOUNE, Y. Detection of viral genomes of caprine arthritis-encephalitis virus (CAEV) in semen and in genital tract tissues of male goat. Theriogenology, v.69, n.4, p.473-480, 2008.

ALI AL AHMAD, M.Z.; CHEBOULNE, Y.; BOUZAR, B.A.; BARIL, G.; BOUVIER, F.; CHATAGNON, G.; LEBOEUF, B.; PEPIN, M.; GUIBERT, J.M; RUSSO, P.; MANFREDI, E.; MARTIN, J.; FIENI, F. Lack of risk of transmission of caprine arthritis-encephalitis virus (CAEV) after an appropriate embryo transfer procedure. Theriogenology, v.69, n.4, p.408-415, 2008.

ANDRIOLI, A. Vírus da artrite encefalite caprina: PCR e isolamento viral em amostras de sêmen, fluido uterino e embriões. 2001.68 f. Tese (Doutorado) - Universidade Federal de Minas Gerais, Belo Horizonte.
ANDRIOLI, A.; GOUVEIA, A.M.G.; MOURA SOBRINHO, P.A. Transferência de embriões em cabras naturalmente infectadas pelo lentivírus caprino. Revista Brasileira de Medicina Veterinária, v.24, n.5, p.215-220, 2002.

ANDRIOLI, A.; GOUVEIA, A.M.G.; MARTINS, A.S.; PINHEIRO, R.R.; SANTOS, D.O. Fatores de risco na transmissão do lentivírus caprino pelo sêmen.Pesquisa Agropecuária Brasileira, v.41, n. 8 , p.1313-1319, 2006.

BARLOUGH, J.; EAST, N.; ROWE, J.D.;VANHOOSEAR, K.; DEROCK, E.; BIGORNIA, L.; RIMSTAD, E. Double-nested polymerase chain reaction for detection of caprine arthritis encephalitis chain reaction for detection of caprine arthritis encephalitis virus proviral DNA in blood, milk, and tissues of infected goats. Journal of Virological Methods, v.50, p.101-113, 1994.

FIENI, F.; ROWE, J.; VAN HOOSEAR, K.; BURUCOA, C.; OPPENHEIM, S.; ANDERSON, G.; MURRAY, J.; BONDURANT, R. Presence of caprine arthritis-encephalitis virus (CAEV) proviral DNA in genital tract tissues of superovulated dairy goat does. Theriogenology, v.59, n.7, p.1515-1523, 2003.

GOUVEIA, A.M.G.; MELO, L.M.; PIRES, L.L.; PINHEIRO, R.R. Microimunodifusão em Gel de Agar para o diagnóstico sorológico de infecção por Lentivírus de Pequenos Ruminantes. In: CONGRESSO BRASILEIRO DE MEDICINA VETERINÁRIA, 27, 2000, Águas de Lindoia. Anais do Congresso Brasileiro de Medicina Veterinária. Águas de Lindoia, 2000. p.33. 
LAMARA, A.; FIENI, F.; MSELLI-LAKHAL, L.; TAINTURIER, D.; CHEBLOUNE, Y. Efficient replication of caprine arthritisencephalitis virus in goat granulosa cells. Virus Research, v.79, n. 1-2, p.165-172, 2001.

LAMARA, A.; FIENI, F.; MSELLI-LAKHAL, L.; TAINTURIER, D.; CHEBLOUNE, Y. Epithelial cells from goat oviduct are highly permissive for productive infection with caprine arthritisencephalitis virus (CAEV). Virus Research, v.87, n.1, p.69-77, 2002.

PETERSON, K.; BRINKHOF, J.; HOUWERS, D.J.; COLENBRANDER, B.; GADELLA, B.M. Presence of pro-lentiviral DNA in male sexual organs and ejaculates of small ruminants. Theriogenology, v.69, n.4, p.433-442, 2008.

PINHEIRO, R.R. Vírus de Artrite Encefalite Caprino: Desenvolvimento padronização de ensaios imunoenzimáticos (ELISA e Dot-Blot) e estudo epidemiológico no Estado do Ceará. 2001. 115 f. Tese (Doutorado) - Escola de Veterinária, Universidade Federal de Minas Gerais.

ROBINSON, W.F.; ELLIS, T.M. Caprine arthritis-encephalitis virus infection: from recognition to eradication.Australian Veterinary Journal, v.63, n.8, p.237-241, 1986.

RODRIGUES, A.S.; SANTOS, V.W.S.; BRITO, R.L.L.; DIAS, R.P.; BRITO, I.F.; ANDRIOLI, A.; PINHEIRO, R.R. Comparação de dois testes sorológicos na evolução natural de caprinos leiteiros com o vírus da Artrite-Encefalite Caprina - dados preliminares. In: SINCORTE, 4, 2009, João Pessoa, Anais... João Pessoa, 2009.

SALTARELLI, M.; QUERAT, G.; KONINGS, D.A.; VIGNE, R.; CLEMENTS, J.E. Nucleotide sequence and transcriptional analysis of molecular clones of CAEV which generate infectious virus. Virology, v.179, p.347-364, 1990.

SIDER, L. H.; VERAS, A.K.A.; SOUZA, K.C.; OLIVEIRA, E.L.; BRITO, R.L.L; NETO, V.P.F.; PINHEHIRO, R.R.; ANDRIOLI, A. Processamento de amostras provenientes do trato reprodutivo feminino para extração de RNA genômico do vírus da artrite-encefalite caprina e diagnóstico molecular por RTnested PCR. Sobral, Comunicado técnico. EMBRAPA-CNPC, 2010, n.117, 5 p.

SOUZA, K. C.; PINHEIRO, R. R.; SANTOS, D. O.; BRITO, R. L. L.; RODRIGUES, A. S.; SIDER, L. H.; PAULA, N.R. O.; AVILA, A. A.; CARDOSO, J. F. S.; ANDRIOLI, A. Transmission of the caprine arthritis-encephalitis virus through artificial insemination.Small Ruminant Research, v.109, p.193-198, 2013.

ZHANG, Z.; SCHWARTZ, S.; WAGNER, L.; MILLER, W. A greedy algorithm for aligning DNA sequences. Journal of Computational Biology, v.7, n. 1-2, p. 203-14, 2000. 